\title{
Livestock owners' Perceptions in Relation to Ghibe - III Hydroelectric Dam, on Bovine Trypanosomosis, Southern Ethiopia
}

Solomon Mekuria ( $\sim$ solmk2010@gmail.com )

Hawassa University

\section{Research Article}

Keywords: Community perception, Ghibe-III dam, Trypanosomosis, upstream and downstream, South Ethiopia

Posted Date: February 10th, 2022

DOI: https://doi.org/10.21203/rs.3.rs-1232753/v1

License: (c) (1) This work is licensed under a Creative Commons Attribution 4.0 International License.

Read Full License 


\section{Abstract}

Background: Trypanosomosis is affected sub-Saharan African countries which denied vast areas of land from livestock and crop production including Ethiopia. The problem prevails mainly in main Rivers like the Ghibe-Omo rivers. The study was conducted in Loma and Kindo Didaye near the Ghibe-III hydroelectric dam, from upstream and downstream, respectively; from January 2019 to June 2020. A standardized questionnaire survey was employed to collect relevant information. Two hundred questionnaires were administered.

Results: A total of 189 questionnaires were returned. Each questionnaire contained 21 questions that include the biography, livestock species and population before and after dam construction, major livestock diseases, clinical signs, transmission, seasonality, susceptibility among species, control practice, type and cost of drugs, treatment frequency and wildlife population status were assessed. Data were analyzed using Mann Whitney U Test. The majority of the interviewee were male with an average age of 39.4+ 10.6 and livestock owners. Herd/flock sizes were non-significantly different before dam construction between the two districts; whereas, the large herd size above six cattle increased by $85 \%$ (77/90) in Loma but decreased by 33.3\% (33/99) in the Kindo Didaye district after dam construction. Bovine trypanosomosis ranked first among major diseases. Knowledge on clinical signs, transmission, and seasonality of trypanosomosis was in agreement with the literature and experience was not significantly $(p>0.05)$ different between the two districts. Diminazine and Trypamidium were the cheapest and frequently used trypanocidal, accordingly. The majority of the respondent (57.8\%) treat animals twice per month per animal indicates the severity of disease, under-dosing or drug resistance problem in the area. $87.8 \%$ of respondents in Loma perceived the reduction of trypanosome prevalence and tsetse population; whereas $77 \%$ of Kindo Didaye respondents perceived no change in prevalence after dam construction. Reduction of wildlife population perceived on upstream than downstream. Health services improved, disease outbreaks and cattle deaths reduced, fishing started following dam construction.

Conclusion: there was a change in health status and wildlife population upstream than downstream indicates the dam impact. The frequency of treatment was also reported. Therefore, monitoring of the disease prevalence and drug resistance study is recommended.

\section{Introduction}

African animal trypanosomosis is one of the economically important livestock diseases in sub-Saharan African countries [1]. The disease is mainly caused by T.brucei, T.congolense, T.vivax, and are transmitted cyclically by the tsetse fly (Glossina spp)[2]. Nearly 37 sub-Saharan African countries and their productive lands are denied from livestock and crop production due to trypanosomosis and its vector tsetse fly. Cattle production in Africa plays a significant role in crop production through draught power, beyond their meat, milk, manure and economic value[3]. Despite their inevitable economic role, livestock diseases in general and animal trypanosomosis, in particular, remain stumbling blocks to promote the livestock production sub-sector[1]. Animal trypanosomosis affects negatively due to mortality, retarded growth rate, 
reduced reproductive performance and low milk production and poor draught power [4]. It is estimated to reduce cattle density by $37-70 \%$, off take by $50 \%$ and reduce the calving rate and increase calf mortality by $20 \%$ [3].

In Ethiopia, tsetse and trypanosomosis are widely distributed in North-Western, Western and SouthWestern regions following main Rivers and their tributaries. Didessa - Blue-Nile, Baro - Akobo, Gojeb Omo and their tributaries are among many other infested areas; hence livestock and crop production are severely affected [5]. Due to poor health coverage in most trypanosomosis affected area, the responsibility of health management mainly falls to livestock owners. Such drug administration is in the hands of farmers or extension workers, who are unskilled in differential diagnosis and lack of knowledge on appropriate drug use [6], which leads to under-dosing and fostering drug resistance. Different control strategies implemented mainly supported by donors with a small participation of communities have resulted in little success. The failure of control activities due to uncoordinated and fragmented control activities, and reinvading ability tsetse after the end of project is the main reason [7]. The success and sustainability of the project depends on community participation. Creating community awareness and active participation in decision making, planning, implementing and evaluating a project intended is very important [8]. In line with this community perception of impact of Ghibe-III dam on bovine trypanosomosis and understanding the cause, clinical signs, transmission, seasonality, treatment and type of drugs in use is paramount important. Therefore, questionnaire survey was designed to understand community perception on the impact of the Ghibe-III hydroelectric dam, on animal trypanosomosis and to assess major livestock, causes, clinical signs, transmission, seasonality and drug usage.

\section{Material And Methods}

\section{Study area}

Two districts were used for this study. Kindo Didaye and Loma districts are located in Wolayta and Dawro zones, respectively; as shown in figure 1. The study area encompasses two physical features due to the presence of Ghibe-III hydro-electric dam; where Loma located in upstream (reservoir) side which is covered by water reserved. Loma has 36 peasant associations and four towns. Out of these 9 PAs' bordering Omo River near Ghibe-III water reserve side. Loma district has four tributaries that supply Omo River. Namely: Kareta, Mala, Manta and Gindera rivers. Despite trypanosome and other diseases in the district, it was endow with livestock population according to the district veterinary officials. Accordingly, Cattle 183,832, Ovine 74,943, Caprine 92,768, Equine 18,205 and Poultry 207, 927 animal population was recorded (Loma district Livestock resource office annual report, 2017). Kindo Didaye is located on the downstream (below the dam) side, where the ecosystem remained more or less naturally intact except due to seasonal bushfires. According to veterinary officials' livestock population in the district record indicate: Cattle 113,122, Ovine 11,298, Caprine 24,452, Equine 6,186 and Poultry 96,504 (District livestock resource office report). The district has 20 Peasant associations and 3 towns. Thirteen PAs were affected by trypanosomosis disease in the district. Of these PA's seven of them were known to border Omo River. 


\section{Climate}

The amount of rainfall decreases throughout the Omo-Ghibe catchments with a decrease in elevation and varies from a minimum of $1,200 \mathrm{~mm}$ to a maximum of about $1,900 \mathrm{~mm}$. The average annual rainfall calculated over the whole Ghibe III basin where the dam is located is $1,426 \mathrm{~mm}$. 75 to $80 \%$ of the annual rainfall occurs during a five months period from May to September. The mean annual temperature is $20.4^{\circ} \mathrm{C}[9]$.

\section{Fauna and flora in the study area}

Wildlife's in this study area are not populous like that of game reserve area in Mago and Omo national wildlife reserve area. However, different wild animals have been recorded at various levels of density. Among mentioned wildlife's; warthog, guzzles (greater kudu), buffalo, lion, deer, fox, apes, monkey, hyena etc were included. Vegetation was a good habitat for diverse wildlife species except those threatened by wildfires during the dry season. On top of bushfires, intensive human activities at the time of dam construction affected the habitat, especially in the upstream area. At the time of deforestation, before water reservation started, wildlife pushed from their original place towards the downstream where there were lesser human activities.

On the other hand, various species of flora were recorded in Omo-Ghibe Valley [9]. Among these riparian vegetation covers $(8.8 \%)$, and deciduous woodland covers about $(82.2 \%)$ and it is characterized by approximately $2 \%$ tree cover and $98 \%$ grass. River/ water body covers $4.3 \%$ of the reservoir area. Farming practices and settlement are concentrated in areas outside the valley at $1100 \mathrm{~m}$.a.s.l and above. Dense vegetation and tickets are concentrated between the reservoir and farming activities with the range of 880 to 1000 m.a.s.I. Trees found near the reservoir are more diversified, due to moisture and suitable environment. The altitudinal ranges, temperature, humidity and the composition of the vegetation in the reservoir area provide ideal conditions for tsetse fly infestation. During the study period, about 150-meter altitudinal difference created due to water reservoir from the previous riverbank to the current reservoir fringe, 200sqm area water has covered a lot of gorges, wildlife habitats including tsetse breeding sites and it is assumed tsetse population and trypanosomosis challenge may reduce due to this environmental shock until the survivors regain /adapt new environment.

\section{Study population and design}

Smallholder farmers located in selected PA's of both Loma and Kindo Didaye districts near the Ghibe-III dam, where people near to water reserve site (the upstream) and below the dam (downstream), were considered. Animal owners were selected randomly using a lottery system after being listed in each selected tsetse and trypanosomosis affected peasant associations. A cross-sectional study design was used for this particular questionnaire survey. Herd/flock size before/after dam construction, major diseases, perception on trypanosomosis and the tsetse fly, cause and seasonality of trypanosomosis and other related questions included. 
The study area was stratified into two, Ghibe-III dam constructions being as a reference point, where Loma district in the upstream and Kindo Didaye district in the downstream. The sample size for questionnaire survey was determined using the formula given by Arsham (2006)[10] with the assumption of $5 \%$ standard error, and the study considers $95 \%$ confidence interval. For an item scored $0 / 1$ for no/yes, the standard deviation of the item scores is given by $S D=(p(1-p) / n)^{1 / 2}$ where $p$ is the proportion obtaining a score of 1 , and $n$ is the sample size. The standard error of estimate SE (the standard deviation of the range of possible $p$-values based on your sample estimate) is given by SE= SD/ $\sqrt{ }$. Thus, SE is at a maximum when $p=0.5$. Thus the worst case scenario occurs when $50 \%$ agree, $50 \%$ disagree. The sample size, $n$, can then be expressed as largest integer less than or equal to $0.25 / \mathrm{SE}^{2}$. Therefore, $\mathrm{SE}$ of $5 \%$ given as follows:

$$
\mathrm{n}=\frac{0.25}{\mathrm{~s}_{\mathrm{E}}^{2}}=\frac{0.25}{(0.05)}=\frac{0.25}{0.0025}=100
$$

Accordingly, 100 animal owners were interviewed in each district. Most statisticians agree that the minimum sample size to get any kind of meaningful result is 100 . Therefore we used a total of 200 questionnaires administered in two districts since the household populations in each district were above 500 households, the sample size was doubled to represent sufficiently.

\section{Questionnaire administration}

Livestock owners' perceptions were assessed using a semi-structured open and closed questionnaire survey from January 2019 to June 2020. Face to face interview method was used to generate information from individuals in the selected peasant association of Loma and Kindo Didaye districts. Each questionnaire contained 21 questions. The first five questions were about interviewee biography; age, gender, primary occupation, spp and number of livestock owned before and after dam construction, major diseases that were encountered in the area included. The next eight questions were related to bovine trypanosomosis, clinical signs mean of transmission, seasonality, susceptibility among livestock owned. The last group of questions included the effect of the dam on trypanosomosis, the status of wildlife population, control practice, cost of drug and frequency of treatment per month, drug availability and most commonly used trypanocidal drugs were recorded.

\section{Data analysis}

Information obtained from the questionnaire survey was entered into a Microsoft Excel spreadsheet and summarized using descriptive statistics. Farmers reported major cattle diseases using local terms; translated to the equivalent English terms were used in the analyses based on the clinical sign they have mentioned for each disease. For instance, to mention trypanosomosis disease, farmers described as gulfo or shulula, or gundia and the name "Eduxinia or Chibebia" for tsetse fly which was stated as the cause of trypanosomosis. 
Farmers' disease diagnosing capacity was either accepted when consistent with the clinical signs described by the reference book or rejected if the responses were inconsistent with the clinical signs. After farmers have mentioned diseases, they have to describe the clinical signs to fit with the standardized clinical sign e.g. descriptions such as 'emaciation, staring coat hair and weakness' were the most common signs for trypanosomosis described by farmers. Each clinical sign was then compared within the given two reference veterinary texts $[1,11]$. A farmer's diagnosis was accepted when at least half of the clinical signs described were consistent with those given in reference texts, otherwise, it was rejected. In this respect, all clinical signs were given equal weight. The type of drug they used against trypanosomosis, the frequency of treatment per month and the most common drugs available in the area were summarized by pie chart and bar graph to compare the two districts.

Non-parametric $U$ test employed to compare response frequency between two districts,whether the response is different or not.The test statistic for the Mann Whitney UTest is denoted by the $U$ value wherethe smaller of $\mathrm{U} 1$ or $\mathrm{U} 2$ used as a test statistic to compare with the critical value from the table at $95 \%$ confidence interval $(a=0.05)$. Where: $U 1$ and $U 2$ defined as $U 1=n_{1} n_{2}+n_{1}\left(n_{1}+1\right) / 2-R_{1}, U 2=n_{1} n_{2}+$ $n_{2}\left(n_{2}+1\right) / 2-R_{2}$ : Where $R_{1}=$ sum of the ranks for district 1 and $R_{2}=$ sum of the ranks for district 2 . $n=$ total number of observation, $n_{1}=$ number of observation in district one and $n_{2}=$ number of observation in district two. The test is considered to be significant when the calculated $U$-value is less than the critical value [12].

\section{Ethical consideration}

The permission to carry out this study was granted by the research ethics review committee of the College of Veterinary Medicine and Agriculture of the Addis Ababa University (Reference number: VM/ERC/05/20/11/2018). The study used those ethical approaches, which have been documented by Rollin [13] as a guide line. The objectives of this study were well explained to all participating farmers and informed consent, for willful participation in the questionnaire interview and discussion, was obtained from participants prior to the beginning of the study.

\section{Results}

\section{Farmers' characteristics}

Out of 200 questionnaires administered 99 and 90 questionnaires were responded from Kindo Didaye and Loma districts, respectively. The most reason for missed ones was after they started the interview they fail to complete the response due to suspicion or were unable to understand the existing situation in the area due to lack of knowledge or recently arrived.

The age group of the interviewee ranges from 25 to 70 years. In Kindo Didaye the 99 interviewees had an average age of $39.4 \pm 10.6$ and range from 25 to 70 years of old, among them 14 were female and 85 were male; whereas in Loma 90 interviewees had an average age of $43.1 \pm 9.93$ and ranges from 26 to 70 
years of old, out of these 6 females and 84 male farmers participated. All of them were either owned livestock or took the responsibility of their relatives to keep animals.

\section{Perception on livestock herd size before and after dam construction}

Data generated from the questionnaire survey indicate that livestock production systems in both districts were based on a free-grazing system. Only kids, calves and weak animals stay around the homestead while all adults were allowed to move toward free grazing land near to Omo-Ghibe River. In these two districts, tributaries and the main river are used as water sources for their animals. All livestock species kept in both districts were local breeds and breeding practice is using the natural mating technique. Animals were kept to build economic status, serve as a source of food through milk and meat. There was little draught power activity due to inaccessible and rugged land topography. The most common cereal crops produced were sorghum and maize, but production was very limited due to ragged and narrow arable land. Especially in Kindo Didaye landholding was very narrow, because of land shortage they use to plant more root crops. In the Loma district, communities keep their animals on the grazing site for long period near the artificial Lake created by the Ghibe-III dam. At night animals are kept in the open-air collecting pen. Animals were allowed to come back homestead either for mass vaccination or treatment and/or if a cow was at trimester pregnancy and a milking cow. Whereas, Kindo Didaye district farmers near to the downstream do keep their animals in the homestead but daily move down to the riverside for grazing and brought back to home at night.

Farmers' responses showed they owned different herd size before six years and in recent years. Accordingly, the opinions of interviewee in two districts were described as follows. In the Kindo Didaye district majority of them had more experience in keeping cattle followed by goats and poultry than sheep and equine. However, the herd and flock size was limited within small ( $<5)$ and medium (6-20) herd sizes, currently, no one among 99 interviewed had a large herd size. Six interviewees had a large cattle herd size before six years; currently, thirty-three (33.3\%) HH had medium cattle herd size and none (0\%) of the respondents had large herd size at the time of data collection. Goat, sheep and poultry flock size were also dominated by small flock size. Such flock and herd size shift from medium and large size to small herd size in Kindo Didaye district might be an indicator of the severity of disease problems associated with rampant animal trypanosomosis prevalence in the area.

It was observed that livestock ownership before dam construction in both study districts had no significant difference ( $p>0.05$ ) as shown in Table 1. However, following the construction of the dam, livestock herd size has decreased in Kindo Didaye District (downstream the dam) while cattle ownership appear to have improved in Loma District (upstream). Accordingly, the sum of medium and large herd size compared, in Loma district, out of 90 respondents 77(85\%) of them had greater than 6 cattle herd size after dam construction compared to the percentage before dam construction 62(69\%) which was significantly $(p<0.05)$ higher at present than before. Conversely, in Kindo Didaye district, out of 99 respondents within the district, 33(33.3\%) of them had greater than 6 cattle herd size after dam 
construction compared to the proportion before dam construction 53(53.6\%), which was significantly $(p<0.05)$ reduced after dam construction.

The proportion of questionnaire survey respondents having sheep and goat flock size of greater than or equal to six has significantly increased after dam construction in Loma District $(p<0.05)$. On the other hand, respondents in Kindo Didaye have seen a decline in goat ownership while there was no change for sheep herd size following the construction of the Ghibe - III dam.

Table 1: livestock herd size owned by respondents in Kindo Didaye and Loma districts after and before dam construction 
Frequency of respondents (percentage)

\begin{tabular}{|c|c|c|c|c|c|}
\hline \multirow[t]{2}{*}{ spp } & \multirow{2}{*}{$\begin{array}{l}\text { Herd/flock } \\
\text { Size/ HH }\end{array}$} & \multicolumn{2}{|c|}{ After dam con. } & \multicolumn{2}{|c|}{ Before dam con. } \\
\hline & & Kindo Didaye & Loma & Kindo Didaye & Loma \\
\hline \multirow[t]{4}{*}{ Cattle } & 0 & $1(1.01 \%)^{a, c}$ & $2(2 \%)^{b, c}$ & $4(4.04)^{a, d}$ & $8(8.9)^{b, d}$ \\
\hline & $1 \leq 5$ & $65(65.7 \%)^{a, c}$ & $11(12.2 \%)^{b, c}$ & $42(42.42)^{a, d}$ & $25(27.8)^{b, d}$ \\
\hline & $6 \leq 20$ & $33(33.3 \%)^{a, c}$ & $54(60 \%)^{b, c}$ & $47(47.5)^{a, d}$ & $53(58.9)^{b, d}$ \\
\hline & $>20$ & 0 & $23(25 \%)^{b, c}$ & $6(6.1)^{a, d}$ & $9(10)^{b, d}$ \\
\hline \multirow[t]{4}{*}{ Goat } & 0 & $49(49.9 \%)^{a, c}$ & $8(8.9 \%)^{b, c}$ & $61(61.61)^{a, d}$ & $13(14.4)^{b, d}$ \\
\hline & $1 \leq 5$ & $48(48.1 \%)^{a, c}$ & $18(20 \%)^{b, c}$ & $32(32.32)^{a, d}$ & $50(55.6)^{\mathrm{b}, \mathrm{d}}$ \\
\hline & $6 \leq 20$ & $2(2 \%)^{a, c}$ & $56(62.2 \%)^{b, c}$ & $7(7.07)^{a, d}$ & $26(28.9)^{b, d}$ \\
\hline & $>20$ & 0 & $8(8.9 \%)^{b, c}$ & 0 & $1(1.1)^{b, d}$ \\
\hline \multirow[t]{4}{*}{ Sheep } & 0 & $85(85.5 \%)^{a, c}$ & $36(40 \%)^{b, c}$ & $93(93.5 \%)^{a, d}$ & $58(64.4 \%)^{b, d}$ \\
\hline & $1 \leq 5$ & $14(14.5 \%)^{a, c}$ & $41(45.6 \%)^{b, c}$ & $6(6.5 \%)^{a, d}$ & $29(32.2 \%)^{b, d}$ \\
\hline & $6 \leq 20$ & 0 & $13(14.4 \%)^{b, c}$ & 0 & $3(3.4 \%)^{b, d}$ \\
\hline & $>20$ & 0 & 0 & 0 & 0 \\
\hline \multirow[t]{4}{*}{ Poultry } & 0 & $51(51.5)^{a, c}$ & $4(4.4)^{b, c}$ & $71(71.7)^{\mathrm{a}, \mathrm{d}}$ & $18(20)^{b, d}$ \\
\hline & $1 \leq 5$ & $39(39.4)^{\mathrm{a}, \mathrm{c}}$ & $13(14.4)^{b, c}$ & $20(20.2)^{a, d}$ & $51(56.7)^{\mathrm{b}, \mathrm{d}}$ \\
\hline & $6 \leq 20$ & $9(9.1)^{a, c}$ & $68(75.6)^{b, c}$ & $7(7.1)^{a, d}$ & $19(21.1)^{b, d}$ \\
\hline & $>20$ & 0 & $5(5.6)^{b, c}$ & $1(1.0)^{a, d}$ & $2(2.2)^{b, d}$ \\
\hline \multirow[t]{4}{*}{ Equine } & 0 & $96(96.5)^{a, c}$ & $67(74.4)^{b, c}$ & $96(96.5)^{a, d}$ & $78(86.7)^{b, d}$ \\
\hline & $1 \leq 5$ & $3(3.5)^{a, c}$ & $23(25.6)^{b, c}$ & $3(3.5)^{a, d}$ & $12(13.3)^{b, d}$ \\
\hline & $6 \leq 20$ & 0 & 0 & 0 & 0 \\
\hline & $>20$ & 0 & 0 & 0 & 0 \\
\hline
\end{tabular}

$0=$ with no animal, $1 \leq 5=$ small; $6 \leq 20=$ medium; $>20=$ large herd $/$ flock size per household $(\mathrm{HH})$; Superscript " $a$ and b" compares between two districts at present and before dam construction; whereas superscript "c and d" compares the present and the past values within districts. 


\section{Knowledge on major livestock diseases}

During the semi-structured open and closed questionnaire survey, farmers have listed major livestock diseases chronologically based on significant impacts on their livestock productivity. In both district, all questionnaire respondents have listed main diseases which they perceived prevalent any time in their experience. The first six diseases that were frequently mentioned by respondents were listed in Table 2, while those less frequently mentioned were collectively categorized as "others". Bovine Trypanosomosis ranked first with $97.8 \%$ and $93.4 \%$ followed by Blackleg with the proportion of $85.5 \%$ and $79.8 \%$, in Loma and Kindo Didaye district, respectively. Lumpy skin disease (LSD) was reported with high frequency in Loma compared to Kindo Didaye district. Respondents believed that the presence of the artificial Lake coupled with wind contributed for the multiplication and spread of the vector and hence the disease LSD appeared more West of artificial Lake.

Table 2: List of major livestock diseases, frequency and percentage of the respondents in Loma and Kindo Didaye districts

\begin{tabular}{|lllll|}
\hline & & Loma & & Kindo Didaye \\
\hline Diseases & $\mathrm{n}$ & $\%$ farmers & $\mathrm{n}$ & $\%$ farmers \\
\hline Trypanosomosis & 88 & 97.8 & 93 & 93.4 \\
\hline Blackleg & 77 & 85.6 & 79 & 79.8 \\
\hline Anthrax & 64 & 71.1 & 66 & 66.7 \\
\hline LSD & 73 & 81.1 & 5 & 5.1 \\
\hline FMD & 42 & 46.7 & 12 & 12.1 \\
\hline Pasteurolosis & 47 & 52.2 & 0 & 0 \\
\hline Others* & 5 & 5.6 & 42 & 42.4 \\
\hline
\end{tabular}

* GIT parasite, leech, babesia, bloat and etc. diseases mentioned by at least one farmer; $n=$ frequency of respondents

\section{Knowledge on clinical sign of animal trypanosomosis}

Among the disease listed during questionnaire survey trypanosomosis received the highest frequency and number one priority disease. Knowledge of the community about clinical signs of trypanosomosis was further assessed and frequently mentioned ones were summarized (Table 3). Out of seven clinical signs listed for bovine trypanosomosis, 'emaciation' and 'rough hair coat' were the most frequently mentioned signs. All seven clinical signs listed were consistent with conventional clinical signs written in veterinary text books $[11,14]$. Response differences between two districts were compared statistically using Mann Whitney test. The smaller $U$ test values were compared with tabulated critical values using 
the formula mentioned in the methodology. Therefore, the calculated results of $U_{1}$ and $U_{2}$ values were 17 and 32, respectively. The critical value based on the degree of freedom in two districts $n_{1}=n_{2}=7$ was 8 . Whereas the calculated smaller $U$ value, in this case, was $U=17$. Since, $17>8$, there is no significant difference between the two districts on knowledge of clinical signs listed for bovine trypanosomosis (Table 3).

Table3: Knowledge of the respondents on most frequently mentioned clinical signs of animal trypanosomosis in Loma and Kindo Didaye districts

\begin{tabular}{|c|c|c|c|c|c|c|c|}
\hline \multirow{3}{*}{ Clinical signs } & \multicolumn{3}{|c|}{ Loma(n=90) } & \multicolumn{4}{|l|}{ Kindo Didaye $(n=99)$} \\
\hline & freq & $\mathrm{R}_{1}$ & Response & Clinical signs & freq & $\mathrm{R}_{2}$ & Response \\
\hline & & & $\%$ & & & & $\%$ \\
\hline Emaciation & 88 & 12 & 97.8 & Emaciation & 91 & 14 & 91.9 \\
\hline Swollen lymph node & 64 & 7 & 71.1 & Swollen lymph node & 31 & 5 & 31.3 \\
\hline $\begin{array}{l}\text { Fever and dry } \\
\text { muzzle }\end{array}$ & 72 & 9 & 80 & $\begin{array}{l}\text { Fever and dry } \\
\text { muzzle }\end{array}$ & 9 & 2 & 9.1 \\
\hline Rough coat hair & 83 & 11 & 92.2 & Rough coat hair & 90 & 13 & 90 \\
\hline diarrhea & 69 & 8 & 76.7 & Diarrhea & 8 & 1 & 8.1 \\
\hline Cough/salivation & 77 & 10 & 85.6 & Coughing/salivation & 40 & 6 & 40.4 \\
\hline \multirow[t]{2}{*}{ Others $^{a}$} & 10 & 3 & 11.1 & Others ${ }^{b}$ & 24 & 4 & 24.2 \\
\hline & sum & $=60$ & & & sum & $=45$ & \\
\hline
\end{tabular}

a; alopecia, lacrimation, weakness, stop regurgitation, lethargy,

b; anorexia, shivering, lacrimation, constipation, tail lesion, bloat, death(each of these signs mentioned by at least one farmer)

$\mathrm{R}_{1}=$ group one rank: $\mathrm{R}_{2}=$ group two rank

Knowledge and perception on transmission of bovine trypanosomosis

Majority of respondents in the Loma district associated trypanosomosis transmission with biting fly and tsetse flies (58.9\%) followed by animal contact (25.6\%) during feeding and watering whereas $7.8 \%$ of farmers reported transmission is only through tsetse fly. Whereas $41.4 \%$ of farmers in Kindo Didaye perceived transmission is mainly associated with the watering site and tsetse fly bites (Table 4). In both cases, the route of transmission associated with tsetse and biting flies scored high frequency than others. Knowledge of respondents on animal trypanosomosis transmission was compared between the two districts using $U$ test. Test statistics results of $U_{1}$ and $U_{2}$ were 49.5 and 31.5 , respectively; for Loma and 
Kindo Didaye. The smaller $U$ was 31.5 and compared with tabulated critical value of $n_{1}=n_{2}=9$ with two sided level of significance at $(a=0.05)$. Tabulated critical value of $U$ at 9 degree of freedom is 17. Therefore, $31.5>17$, hence there was no significant $(p>0.05)$ difference in the knowledge and perception of respondents on means of transmission of bovine trypanosomosis.

Table 4: Farmer's perception on transmission of trypanosomosis in Loma and Kindo Didaye districts

\begin{tabular}{|lccccccc|}
\hline Route of transmission & \multicolumn{3}{l}{ Loma=90 } & \multicolumn{5}{c|}{ Kindo Didaye=99 } \\
\hline Transmission of disease & $\mathrm{n}$ & $\mathrm{R}_{1}$ & $\%$ & $\mathrm{n}$ & $\mathrm{R}_{2}$ & $\%$ \\
\hline Animal contact at feeding \& watering & 23 & 15 & 25.6 & 29 & 16 & 29.3 \\
biting and tsetse fly & & & & & & \\
\hline Biting and tsetse fly only & 53 & 18 & 58.9 & 10 & 14 & 10.1 \\
\hline Animal contact, feed \& water & 2 & 7.5 & 2.2 & 5 & 11 & 5.5 \\
\hline Tsetse fly only & 7 & 12 & 7.8 & 8 & 13 & 8.1 \\
\hline Feed and water & 0 & 2.5 & 0 & 1 & 5.5 & 1.1 \\
\hline Water and tsetse fly & 0 & 2.5 & 0 & 41 & 17 & 41.4 \\
\hline Water only & 0 & 2.5 & 0 & 4 & 10 & 4 \\
\hline Others & 3 & 9 & 3.3 & 0 & 2.5 & 0 \\
\hline I don't know & 2 & 7.5 & 2.2 & 1 & 5.5 & 1 \\
\hline & sum & $=76.5$ & & sum & 94.5 & \\
\hline
\end{tabular}

\section{Community perception on seasonality of bovine trypanosomosis}

Individual response of farmer's in both districts revealed about seasonality of trypanosomosis. All respondents agreed trypanosomosis was seasonal; but differed on which season the disease is more prevalent or severe. In Kindo Didaye district, $40 \%$ of respondents' perceived trypanosomosis is more prevalent in dry than rainy season whereas $42 \%$ responded the problem prevails in both dry and rainy season. On the other hand, in Loma district, $62.2 \%$ respondents believed trypanosomosis is more prevalent in rainy season followed by $25.6 \%$ respondents who thought the problem is common in dry season. Few Loma district respondents $(7.7 \%)$ perceived the problem exists in both dry and rainy seasons, and the remaining 3.3\% of respondents couldn't decide in which season the disease exist. Their main reason for seasonality also differs among respondents within two districts. A substantial number of the respondents perceived that drought and feed shortage contributes more to the occurrence of 
trypanosomosis in the dry season; whereas the other group of interviewee conceived trypanosomosis occurrence increases in the rainy season due to increase tsetse population after the rainy season.

Perception on the susceptibility of animal species to trypanosomosis indicates $98 \%$ of respondents in the Kindo Didaye district agreed cattle are the most susceptible followed by goats. Whereas almost all respondents' in the Loma district has mentioned cattle, equine and goats followed by sheep are more susceptible in chronological order.

\section{Community perception and practices on animal health management}

In Loma district $87.8 \%$ respondents perceived trypanosomosis problem reduced significantly because of improved health care through trypanocidal drug treatment and spray via extension health workers in their village. They also believe tsetse fly population reduced since dam construction because of vast area of tsetse suitable vegetation and grazing land covered by water reserve. But $2.5 \%$ of respondent believes water reserve affected their honey production due to deforestation as a result of artificial Lake created. Whereas, in Kindo Didaye $40 \%$ of respondents perceived the reduction of trypanosomosis is due to treatment only and $45 \%$ of respondents believe the reduction is by treatment and spray. Respondent emphasized there is still intensive tsetse challenge and trypanosomosis disease in Kindo Didaye district, and their livelihood remained the same as before.

According to the information from the respondents, the type of trypanocidal drugs commonly used in the area are diminazene aceturate ("kish kish") and trypamidium group ("duluwa") whereas Deltamethrin (pour-on)was mentioned as the most common insecticide spray. All respondents use one or both trypanocidal at least once in a month (Figure 3). Treatment costs also varied among individuals and between districts. The minimum cost recorded was 10 Ethiopian Birr per animal per treatment, and the maximum drug cost was 60 Ethiopian Birr as shown in the pie chart (Figure 2). According to the frequency of response in the Loma district, $97 \%$ of them expend within the range of 10 up to 30 Eth Birr per animal per treatment, whereas in Kindo Didaye only $66 \%$ of them expend within the same range. Few of them spend up to 60 ETH Birr per animal per treatment that was costly. Relatively Kindo Didaye respondents spend more expensive drug costs within a range of 31-60 ETHB (34\%), whereas only $3 \%$ of respondents in the Loma district as shown in Pie chart. This may be associated with relapse of infection, type of drugs available (Trypamidium is more expensive than diminazene) or shortage of drug supply in Kindo Didaye district.

\section{Treatment frequency per month}

In both districts majority of them responded that they treat their animals at least two times per month. $87 / 189(46 \%)$ of them treat their animals twice per month, whereas $56 / 189(30 \%)$ of them treat only once per month. The remaining respondents treat more than twice when a treated animal is not responding to the treatment given. As shown in figure 3 there was little difference between districts. In Kindo Didaye $51 \%$ of them treat once per month and $35 \%$ of them treat twice per month, the remaining respondent treats animals if previously treated animals didn't show improvement it will be treated for the third and 
fourth times per month. One round treatment per month may be associated with effectiveness of drugs and/or proper usage. On the other hand, in the Loma district, the majority $(57.8 \%)$ of them treats twice per month and $26.7 \%$ of them treat three times and more. Very few of them $(5.6 \%)$ responded as they are treating animals once per month. This intensive treatment might indicate the presence of a high disease challenge or there might be drug-resistant trypanosomes circulating in the area and/or there could be also an under-dosing problem or else farmers are more curious to protect their animals before infection developed. Treatment was usually handled by community health workers, animal owners and Animal health assistants at village level.

\section{Community Perception on trypanosomosis and tsetse fly population after dam construction}

Respondents of the two districts mentioned the change existed on disease trypanosomosis after the dam construction. $70.7 \%$ of respondents in the Kindo Didaye district believed that there is no reduction in the prevalence of trypanosomosis and tsetse fly population whereas $29.3 \%$ of respondents believed there is a reduction in prevalence. Among these who don't believe, $64.6 \%$ of them concurred that dam construction has no effect on the reduction in their village.

Whereas, in the Loma district $87.8 \%$ of the respondents believed that there is a reduction in the prevalence of trypanosomosis and tsetse population; of these $77.8 \%$ of them agreed that dam has contributed to the reduction of trypanosomosis prevalence and tsetse population. Whereas $12.2 \%$ disagree about the reduction of the problem and they believe also dam construction has no effect on prevalence reduction as shown in Table 5.

Table 5: Frequency of respondents about reduction of trypanosomosis prevalence and tsetse population after dam construction in the study site

\begin{tabular}{|llllll|}
\hline Study site & $\mathbf{n}$ & \multicolumn{2}{l|}{ Is there reduction of tryps* \& tsetse } & \multicolumn{2}{l|}{ Does the dam has effect } \\
\hline Kindo didaye & 99 & $29(29.3 \%)$ & $70(70.7 \%)$ & $35(35.4)$ & $64(64.6 \%)$ \\
\hline Awasho & 29 & 18 & 11 & 14 & 15 \\
\hline Hamaya & 35 & 4 & 31 & 11 & 24 \\
\hline Petere & 35 & 7 & 28 & 10 & 25 \\
\hline Loma & 90 & $79(87.8 \%)$ & $11(12.2 \%)$ & $70(77.8 \%)$ & $20(22.2 \%)$ \\
\hline Zimawaruma & 34 & 28 & 6 & 25 & 9 \\
\hline Denbella Bolla & 21 & 19 & 2 & 18 & 3 \\
\hline Subotulema & 35 & 32 & 3 & 27 & 8 \\
\hline
\end{tabular}

Tryps $^{*}=$ trypanosomosis 
Questionnaire interviewee in both Kindo Didaye and Loma districts shared their experience on wildlife distribution in the area. Some 15 years back the Omo-Ghibe River gorge particularly where Ghibe-III dam built was naturally endowed with abundant fauna and flora. There were different species of wildlife's, including lion, buffalo, woodland antelope, common warthog, bushbuck, Hyena's, monkey, apes and others. However, after ten years due to human activities and deforestation in the area for Ghibe-III hydroelectric dam construction, wildlife populations and diversity was believed to be significantly reduced. According to $87 \%$ of respondents in Loma districts, Lion, lesser Kudu, warthog, buffalo, bushbuck moved from upstream to downstream to the less ecological disturbance due to less human activity. On contrary, monkey and apes significantly increased and moved into human settlement areas. In Kindo Didaye, which is located downstream from the dam, respondents confirmed there is significant change in wildlife population especially following seasonal trends due to natural phenomenon and dam construction. During rainy season when green grass occupies the area, they resume their original place. Hoof print of buffalo and hippo, and dung of greater kudu as well as number of monkey observed during study period (Figure 4).

\section{Other changes following Ghibe III dam construction}

Participants in Loma (upstream) district agreed that veterinary service was better, and animal disease outbreaks and cattle deaths were reduced after dam construction compared to those who perceived that it was good right from the beginning (Table 6), on the contrary, participants from Kindo Didaye revealed no significant change in the perception on the above events despite better animal health services.

Fishing practice started after dam construction in upstream where water reserve favored them to fishing.

Table 6. Event comparison before and after Ghibe III dam construction in both Loma (upstream) and Kindo Didaye(downstream) using median score.

\begin{tabular}{|c|c|c|c|c|}
\hline \multirow[b]{2}{*}{ Events } & \multicolumn{2}{|c|}{ Upstream } & \multicolumn{2}{|c|}{ Downstream } \\
\hline & Before* & After* & Before* & After* \\
\hline Satisfaction on animal health services & $8(6-12)$ & $\begin{array}{l}22(18- \\
24)\end{array}$ & $10(7-13)$ & $20(17-23)$ \\
\hline Occurrence of animal diseases outbreaks & $\begin{array}{l}18(16- \\
24)\end{array}$ & $12(6-14)$ & $16)^{14(8-}$ & $22)^{16(14-}$ \\
\hline Number of cattle deaths & $\begin{array}{l}21(17- \\
23)\end{array}$ & $9(7-13)$ & $\begin{array}{c}17(14- \\
19)\end{array}$ & $13(11-16)$ \\
\hline Fishing & 0 & 30 & 0 & 0 \\
\hline
\end{tabular}

* Values $=$ median score and ranges

\section{Discussion}




\section{Livestock population}

Livestock production was more important component of agriculture in both districts. Community perception indicates that cattle population was more dominant followed by goats and poultry, whereas sheep were very small. This agrees with the data reported [15] for both Wolayta and Dawro Zones.

According to questionnaire survey responses cattle herd size holding before dam construction was not significantly different between Loma (upstream) and Kindo Didaye (downstream). Whereas, after dam construction, most of the respondents agreed that farmers with cattle herd sizes greater or equal to six were significantly higher in Loma than Kindo Didaye district. In agreement with this observation within district comparison before and after dam construction was made, farmers with cattle herd sizes greater or equal to six have significantly increased after dam construction in Loma district, whereas in Kindo Didaye farmers with such cattle herd size have declined. Loma is a district located on the side of the dam reservoir (upstream) where the construction process has disrupted the fauna and flora of the area. It is not clear, if such changes have created favourable conditions such as improved feed availability, reduced diseases occurrence, etc in this area compared to the downstream district, Kindo Didaye. The finding is in agreement with Maudlin, et al. (2005)[16], though there could be variation from place to place, trypanosomosis has a significant negative impact on livestock population growth. Swallow(2000)[3] in his socio-economic impact assessment study indicated trypanosomosis and tsetse challenge affect livestock population growth, reduction on market off taking of livestock and others.

\section{Disease knowledge}

Community participants have listed more than six major livestock diseases in the study area. Among the diseases listed, bovine trypanosomosis had the highest frequency and ranked number one disease priority in both Loma (upstream) and Kindo Didaye (downstream). This was followed by blackleg, anthrax, LSD and FMD accordingly. Community response was in agreement with recent study conducted in Dawro zone $[17,18]$ have also indicated that trypanosomosis is a major problem in the study area. In Kaffa and Bench Maji zone, which is adjacent to the current study area, $94.1 \%$ of questionnaire survey respondents considered bovine trypanosomosis as an economically important cattle disease accounting for $64.6 \%$ of the total annual deaths in the year $2011 / 2012$ [19]. Similar information was reported in tsetse infested areas elsewhere in sub-Saharan Africa. The study conducted in Kenya [20], Tanzania [21] and Nigeria [22] have shown the same report, indicating trypanosomosis is a major constraint in livestock production. The response of farmer's on the problem of trypanosomosis and tsetse fly correlated with actual situation in study area in Nigeria [23]. Animal trypanosomisis is also prioritized as the most important disease among others in West Africa [24].

\section{Clinical signs, transmission and seasonality}

Questionnaire survey respondents were able to fairly describe the clinical manifestation of trypanosomosis in cattle in both study locations. The majority of the respondents agreed mainly on emaciation and rough coat hair. Knowledge on a swollen lymph node, cough/salivation, fever, loss of 
appetite and diarrhoea were also considered in focus group discussion [25]. Studies in Orma community in Kenya reflected similar clinical signs for chronic trypanosomosis infection but hemorrhage and sudden death for the acute form of the disease [26]. Comparable knowledge was mentioned in the agropastoralist area in Lamwat and Kwale, Kenya [20,24]. The majority of the responses of the communities were also in agreement with existing literature [4, 11, and 14]. Many studies have substantiated that local communities have accumulated knowledge about their animals and their wellbeing [27]. The strong concordance observed between diseases and clinical symptoms listed above strengthens rich indigenous knowledge of the community.

Most participants perceived that animal trypanosomosis is transmitted by tsetse and biting flies followed by tsetse and biting flies, animal contact during grazing and watering period. The response in both districts had no significant difference and it was in agreement with scientific descriptions $[1,11,14]$. Community response finding was also supported by many community perception studies including those in South Western Ethiopia, Serengeti community in Tanzania and in Southern Sudan community [19, 27, 28]. It was also reported that trypanosomosis causes a reduction in productivity of livestock; including reduced milk yield, bodyweight loss, poor hide quality, abortion and costly treatment. Similar observations were recorded in various studies [4]. Other studies have shown that more than half of the study participants incriminated draught power reduction and high drug cost to animal trypanosomosis in Metekel and Guji zones of Ethiopia [29, 30]. Weight loss and milk reduction were also stated by the Nigerian community [23]. Almost all respondents agreed the occurrence of trypanosomosis and its cause of transmission depends on season mainly in the long rainy season which is in agreement with $[19,25]$. Seasonal observation in the same study site showed a significantly high prevalence of trypanosomosis and high tsetse and biting fly apparent density observed in the rainy season; furthermore, disease prevalence and vector density were found significantly high in downstream than upstream [31]. Knowledge of farmers observed on signs and transmission in high tsetse challenge area [24], was agreed with current finding; $44 \%$ of farmers agreed tsetse fly accompanied with the river, grazing site and wet season are the main cause of trypanosomosis [32].

\section{Animal health management}

Altogether, the local community in both study sites has adequate experience with bovine trypanosomosis and the disease is considered a major threat to their livestock and their livelihood [27]. To combat this problem, the major control methods employed in the area were reported to be the use of trypanocidal drugs and pour-on insecticide spray. Most farmers buy trypanocidal drugs and treat their animals in both districts, when there is a drug shortage they look for private vender and open markets, similar activities indicated [20]. The dose and the frequency of treatment per month also depend upon their understanding and effectiveness of the drug type used; $53 \%$ of respondents practice inappropriately [32]. Whereas in West Africa apply treatment following appropriate clinical signs [24]. However, farmers lack knowledge on appropriate dosage, poor hygienic injection $[20,24]$. This knowledge gap might have contributed to under dosage and repeated treatment, which could lead to drug resistance. 
The study indicated repeated trypanocidal drug usage especially low-cost drugs originated from different companies reported per month in both districts. Diaminazine aceturate is the cheapest and commonly used in the area followed by Isomethamidium chloride. In total, $46 \%$ of respondents treat twice per month; whereas only $30 \%$ of the respondents experienced treating once per month. Such a high proportion of repeated treatment coupled with farmers' poor preparation and application could contribute to drug resistance development [19]. $41.6 \%$ of farmers experienced treatment failure this was more associated with the use of diminazene aceturate in West Africa [24]. Short half-life in a blood circulation of diminazene aceturate associated with repeated treatment might have contributed to the occurrence of treatment failures. Despite treatment failure still, communities prefer to use drugs at cheap prices. This study shows more than $66 \%$ of respondents in kindo Didaye district spend less than 30ETHBirr per animal per month and $34 \%$ of respondents spend within the range of 31-60ETHBirr; Whereas in Loma district $97 \%$ of respondents expend less than 30ETHBirr per animal per month and only $3 \%$ of them spend above 30ETHBirr. This indicates in the Loma district majority of the respondents prefer cheap drug prices as compared to the Kindo Didaye district. On the other hand, $57 \%$ of Loma district respondents treat twice per month per animal, but $51 \%$ of Kindo Didaye respondents treat once per month per animal. The use of low price drugs and treatment repeatedly could be one of the control strategies before infection advanced; even in Kindo Didaye respondents have an almost similar strategy by treating animals monthly. The finding is in agreement with West African studies, where the most important primary practice used by $49.7 \%$ of farmers, was trypanocidal drugs, either ISMM or repeated doses of DIM during risk periods to protect their animals. Many farmers (41.6\%) had experienced treatment failures and these were more common when using DIM; 78.0\% of farmers reported ISMM always, or almost always, worked [24]. The same reason for treatment failure in this study area might hold due to repeated injection of DIM resulted drug resistance.

\section{Perception of dam impact on trypanosomosis and tsetse fly}

In general, the impact of the dam on animal trypanosomosis and tsetse fly is explained differently by the two districts. The majority of the respondent from the Loma district reported that dam construction and water reserve has reduced disease problem, whereas in the Kindo Didaye district majority of respondents reported there is no change in disease problem due to dam construction. Focus group discussion and seasonal observation in both district has shown similar situation in line with respondents, where there was low prevalence and apparent fly density in Loma than Kindo Didaye district [25, 31]. Other experiences on Mosquito abundance and malaria disease in Ghibe-l hydroelectric dam showed that stagnant water in the dam contributed $88 \%$ for the increase of mosquito thereby increasing malaria cases [33]. Stagnant water might be a favorable environment for mosquito multiplication. Water reserve upstream of Ghibe-III hydroelectric dam could also have the same contribution for mosquito multiplication but tsetse breeding site might have been affected due to water flooded site; since most tsetse burrow moisture sandy area to deposit their puparium inside. International Rivers Networks (2001) [34] indicated that water filling affect plants, animals and agricultural activities in the land covered with water reservoir. This could be the reason for the reduction of tsetse fly apparent density from the water reserve site. Climate changes could also occur as the result of water evaporation in the periphery of the 
reserve, which could contribute to tsetse apparent density. Respondents reported that honey harvest and wild animals reduced substantially on upstream than downstream.

\section{Conclusion}

Local communities in the two study areas have adequately described the livestock population structure and their diseases. Accordingly, cattle herd sizes greater or equal to six have significantly increased after dam construction in the Loma district, whereas in Kindo Didaye farmers with such cattle herd sizes have declined. Bovine trypanosomosis was ranked as the number one disease priority in both Loma (upstream) and Kindo Didaye (downstream) districts. The strong concordance observed between diseases and clinical symptoms listed by the community ensures the presence of rich indigenous knowledge in the community. The majority of the respondent from the Loma/upstream district reported that the impact of the disease and its vectors has significantly reduced after Ghibe- III dam construction while participants from Kindo Didaye district reported no change in disease problem to dam construction.

\section{Declarations}

\section{Ethics approval and consents of the participants}

All methods were carried out in accordance with relevant guidelines and regulations. All research protocols were approved by the research ethics review committee of the College of Veterinary Medicine and Agriculture of the Addis Ababa University (with Ref.no.VM/ERC/05/20/11/2018).

Informed consent was obtained from all participants during interviews.

\section{Consent for publication}

Not applicable

\section{Availability of data and materials}

The datasets generated and/or analyzed during the current study are not publicly available due to risk of data plagiarism, but are available from the corresponding author on reasonable request.

\section{Competing interests}

The author declares that has no competing interests.

\section{Funding}

The research has not been granted. There is no fund ID

\section{Authors' contributions}


SM: Developed the project, wrote the protocol, collected the data during field work, analyzed the data and interpreted the result, and drafted the manuscript and final proof reading of the manuscript before it was submitted to the journal.

\section{Acknowledgments}

My deepest appreciation goes to the community in Kindo Didaye and Loma districts who have actively participated in the questionnaire interview. The author would also like to thank Tsetse and Trypanosomosis Control Institute for providing logistic and technical support. This work was partially supported by the Addis Ababa University under its PhD research support scheme. Apart from this, the research did not receive any specific grant from funding agencies in the public, commercial, or not-forprofit organizations funding.

\section{References}

1. Leak, S.G.A., 1999. Tsetse Biology and Ecology. Their Role in the Epidemiology and Control of Trypanosomosis; Cabi International, 1-599.

2. Urquhart, G.M., Armour, J., Duncan, J.L., Dunn, A.M., Jennings, F.W., 1996. Veterinary Parasitology, 19164. 2nd ${ }^{\text {ed }}$. Blackwell Science.

3. Swallow, BM., 2000. Impacts of trypanosomosis on African agriculture, PAAT technical and scientific series, 2, 52.

4. Peter, H., 2013. Tsetse-transmitted trypanosomes-their biology, disease impact and control. Jour. Invert. path. 112, 11-14; http://dx.doi.org/10.1016/j.jip.2012.07.014

5. Slingenbergh, J., 1992. Tsetse control and agricultural development in Ethiopia. World Anim. Rev. 70-71, 30-36.

6. Van den Bossche, P., Doran, M., Connor, R.J., 2000. An analysis of trypanocidal drug use in the Eastern Province of Zambia. Acta Trop. 75, 247/258

7. Bright, W. B., Dransfield, B., Maudlin, I., Stevenson, P., Shaw, A.P.M., 2001. Reality vs.rhetoric - a survey and evaluation of tsetse control in East Africa. Agric. Human Values.18, 219-33.

8. Dransfield RD, Brightwell R (2004): Community participation in Tsetse control: the principles, potential and practice. In The Trypanosomiasis. Edited by Maudlin I, et al. Wallingford, UK: CAB International Publishing: 533-546

9. EEPA (2009): Ethiopian Electric Power Authority. Executive summary of environmental and social impact assessment of Gibe III hydroelectric dam 1-45. Link: https://bit.ly/3gPKK4c

10. Arsham, H., 2006. Questionnaire design and surveys sampling. 8thed. http://home.ubalt.edu/utsbarsh/stat data/Surveys.htm

11. Radostits, O.M., Gay, C.C., Hinchcliff, K.W., (2010): Veterinary Medicine: A Textbook of the Diseases of Cattle, Sheep, Pigs, Goats and Horses, ninth ed. W.B. Saunders Company Ltd, London, p. 1877. 
12. Seigel, S. and Castellan, N. J., (1994): Non-parametric statistics for behavioural sciences; $2^{\text {nd }}$ edition. McGraw-Hill, New York, USA, pp.

13. Rollin BE: An introduction to Veterinary Medical ethics: Theory and cases. $2^{\text {nd }}$ edition. lowa, USA: Blackwell publishing; 2006:1-315.

14. Soulsby, E. J. L. (1986): Helminths Arthropods and Protozoa of Domesticated Animals, $7^{\text {th }}$ ed Bailliere Tindall,London.

15. Central Statistical Authority, CSA (2018): Agricultural sample survey (2017/18), report on livestock and livestock characteristics

16. Maudlin, I., Peter, H., Miles Michael (2005): The trypanosomosis. CABI publishing, walling ford https://doi.org/10.1016/j.trstmh.2004.09.004

17. Sheferaw, D. Birhanu B., Asrade B., Abera M., Tusse T., Fikadu A., Denberga Y., Gona Z., Regassa A., Mojie N., Kussito E., Mekibib B., Asefa T., Woldesenbet Z., (2016): Bovine trypanosomosis and Glossina distribution in selected area of southern part of rift valley, Ethiopia. Acta tropica; 154: 145148

18. Abebe R., Gute S. and Simon I., (2017): Bovine trypanosomosis and vector density in Omo-Ghibe tsetse belt southern Ethiopia. Acta tropica . 167, 79-85

19. Seyoum Z., Terefe G. and Ashenafi H.(2013): Farmers' perception of impacts of bovine trypanosomosis and tsetse fly in selected districts in Baro-Akobo and Gojeb river basins, Southwestern Ethiopia. BMC Veterinary Research: 9:214

20. Ohaga, S.O., Kokwaro, E.D., Ndiege, I.O., Hassanali, A., Saini, R.K., 2007. Livestock farmers' perception and epidemiology of bovine trypanosomosis in Kwale District, Kenya. Prev. Vet. Med. 80 (1), 24-33.

21. Muangirwa, C.J., Kimaro, E.E., Mujuni, P., Assey, T., Lugembe, K.K.M., Sikay, M., Mwitumba, A.,(2001). Distribution of tsetse flies in Mara Region, north western Tanzania and appraisal of community based intervention. In: Proceedings of the 26th Meeting of the ISCTRC, Ouagadougou, Burkina Faso.

22. Njoku, C.I., Uzoigwe, N.R., Afagbonna, V.N., Abubakar, A., Usman, B., 2003. Community perception of animal trypanosomosis in Durbi village, Jos east Local Government Area of Plateau State, Central Nigeria. In: Proceedings of the $27^{\text {th }}$ Meeting of the ISCTRC, Pretoria, South Africa.

23. Oluwafemi, R. A. llemobade, A. A. and Laseinde, E. A. O (2007): The impact of African animal trypanosomosis and tsetse on the livelihood and well-being of cattle and their owners in the BICOT study area of Nigeria. Scientific Research and Essay Vol. 2 (9), pp. 380-383 http://www.academicjournals.org/SRE

24. Gracea D., Randolpha T., Affognona H., Dramane Dao b, Diall O b., Clausenc Peter-Henning (2009): Characterisation and validation of farmers' knowledge and practice of cattle trypanosomosis management in the cotton zone of West Africa. Acta Tropica 111: 137-143

25. Mekuria S, Ashenafi H, Kebede N, Eyasu T, Terefe G, et al. (2020): The impact of Gibe III hydroelectric dam on the situation of livestock diseases with particular emphasis on bovine trypanosomosis in Southern Ethiopia. Int J Vet Sci Res 6(2): 104-113. DOI: https://dx.doi.org/10.17352/ijvsr.000061 
26. Catley, A., (2006): Use of participatory epidemiology to compare the clinical veterinary knowledge of pastoralists and veterinarians in East Africa. Trop. Anim. Health prod. 38, 171-184.

27. Catley, A., Osman J., Mawien, C., Jones, B.A., Leyland T.J., (2002b): Participatory analysis of seasonal incidences of diseases of cattle, disease vectors and rainfall in southern Sudan Preventive Veterinary Medicine ELSEVIER vol 53: 275-284

28. Dismas L. M., Kinyemi J. K., (2017): Knowledge, attitude, and practices about tsetse control among communities neighbouring Serengeti National Park, Tanzania. Heliyon 3(2017) e00324. doi: 10.1016/j.heliyon.2017. e00324

29. Tesfaye D., Niko S., Reginald D.D., Eric T. (2012): Economic burden of bovine trypanosomosis in three villages of Metekel zone, Northwest Ethiopia. Trop. Anim. Health Prod. 44:873-879 DOI 10.1007/s11250-011-9981-3

30. Mersha C., Dulecha A. and Basaznew B.(2013): Socio-Economic Assessment of the Impacts of Trypanosomiasis on Cattle in Girja District, Southern Oromia Region, Southern Ethiopia. Acta Parasitologica Globalis. DOI: 10.5829/idosi.apg.2013.4.3.7523 vol4 (3): 80-85.

31. Solomon M., Hagos A., Nigatu K., Tesfu K., Dagnachew B D., Tadesse E., Desie Sh., Getachew T., (2021): Bovine trypanosomosis in upstream and downstream of Ghibe-IIl hydroelectric dam: parasitological and entomological study, southern Ethiopia. Veterinary Parasitology: Regional Studies and Reports 23(2021) 100507. www. Elsevier.com/locate/vprsr.

32. Machila N., Wanyangu Samuel W., McDermott J., Welburn Susan C. Ian Maudlin, Eisler Mark C. (2003): Cattle owners' perceptions of African bovine trypanosomiasis and its control in Busia and Kwale Districts of Kenya. Acta Tropica 86: 25-34

33. Yewhalaw D. , Kassahun W., Woldemichael K., Tushune K., Sudaker M., Kaba D., Duchateau L., Bortel W. V., Speybroeck N.,(2010): The influence of the Gilgel-Gibe hydroelectric dam in Ethiopia on caregivers' knowledge, perceptions and health-seeking behaviour towards childhood malaria. $B M C$ Malaria Journal. 9:47http://www.malariajournal.com/content/9/1/47

34. International Rivers Network, 2001. Reviving the world's rivers. International Rivers Net- work Web Site. URL: http://www.revirrevival.org/brochure/rrpt2.html.

\section{Figures}




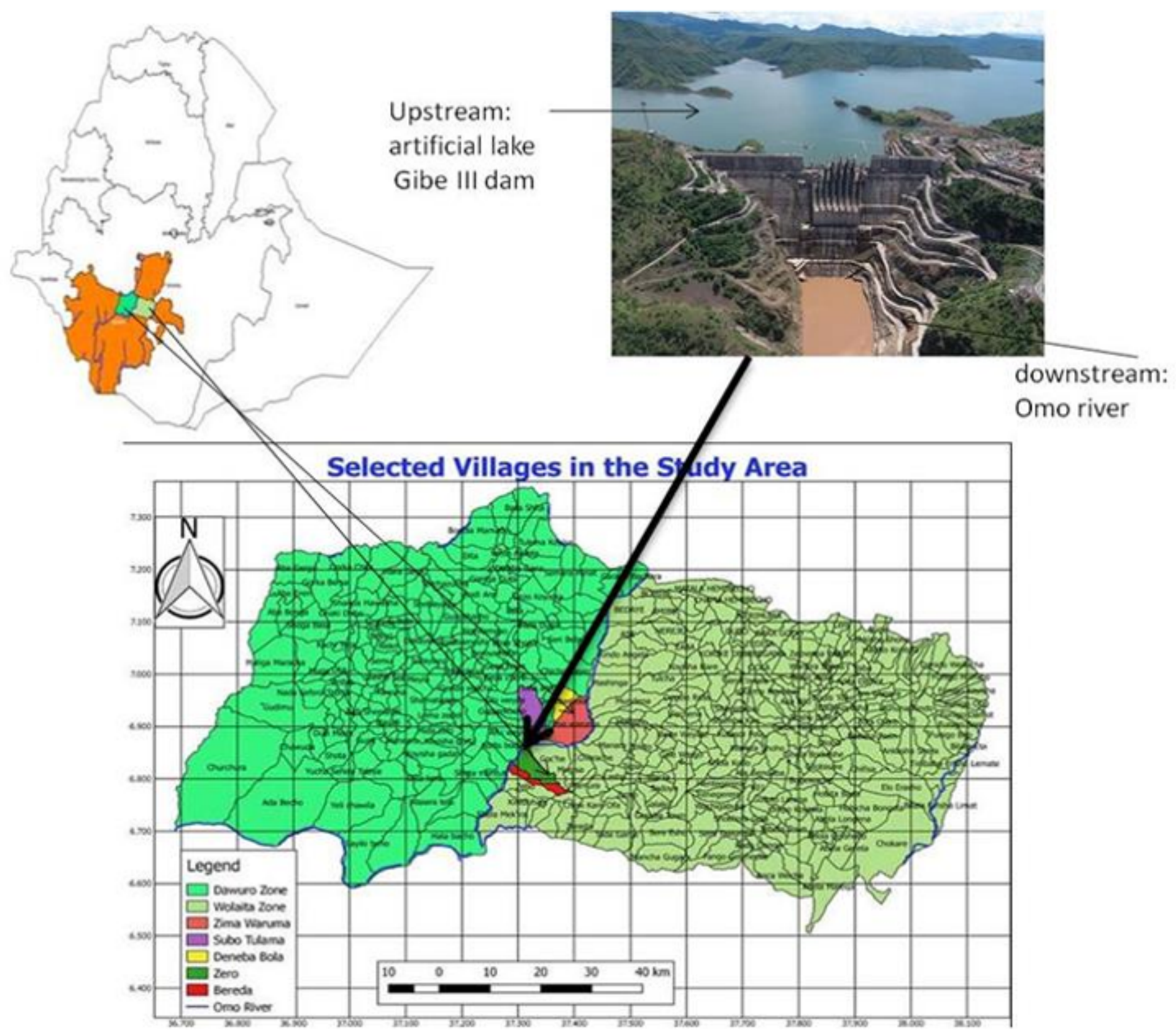

Figure 1

Map of Ethiopia showing study sites in Lomma (left side) and Kindo Didaye (right side) district (Dam image: https://www.salini-impregilo.com). 


\section{Kindo Didaye district}

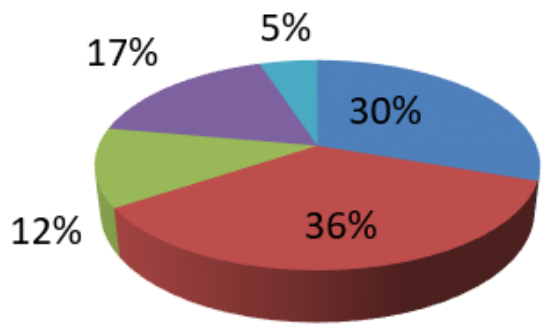

\section{Loma district}

-10-20

- 21-30

- 31-40

41-50

51-60
10-20

- 21-30

- 31-40

41-50

51-60

Figure 2

proportion of farmer's response for ranges of trypanocidal drug cost (ETHB) per animal per treatment in Kindo Didaye and Loma districts, respectively

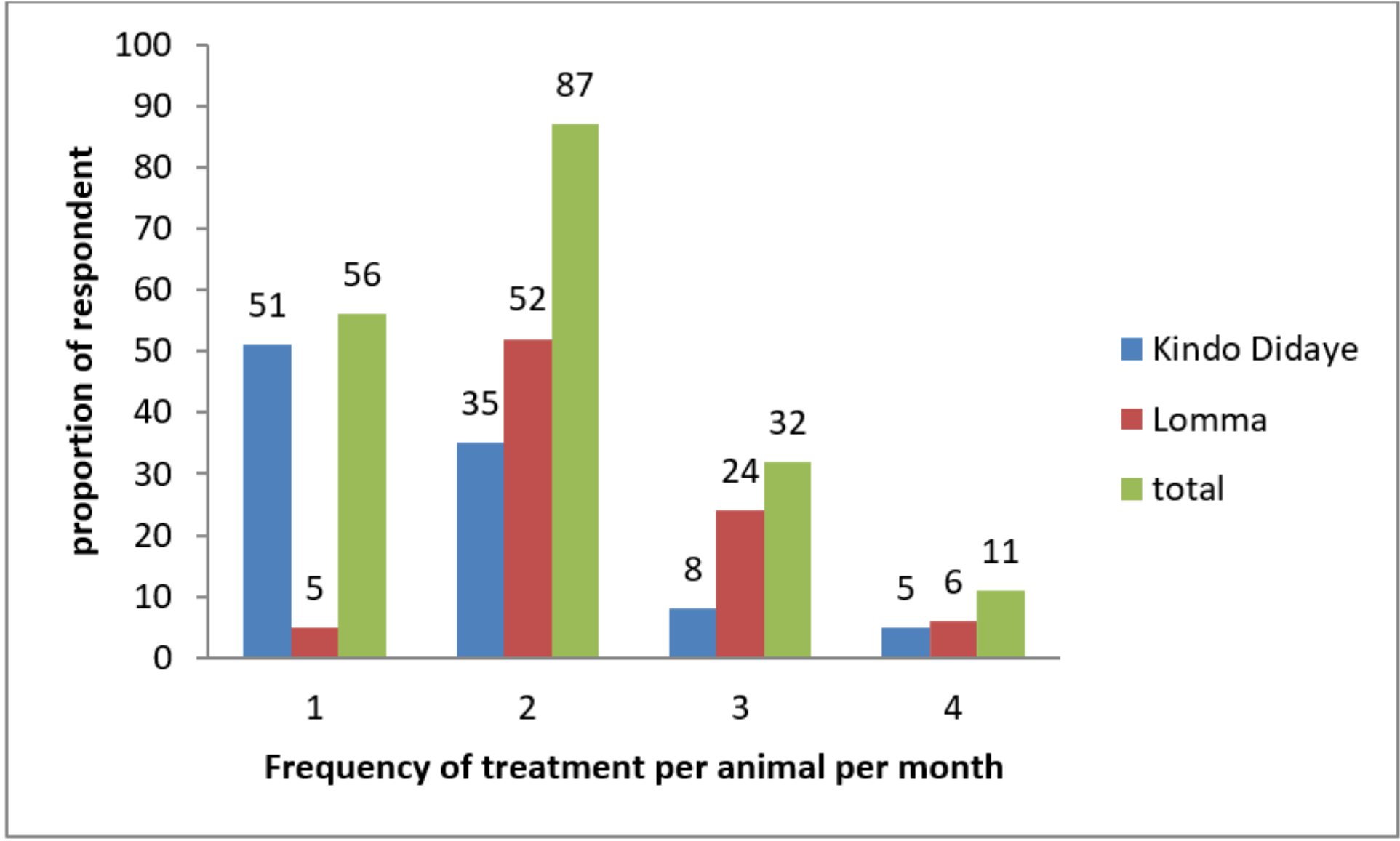

Figure 3

Frequency of treatment per animal per month according to animal owners' response 


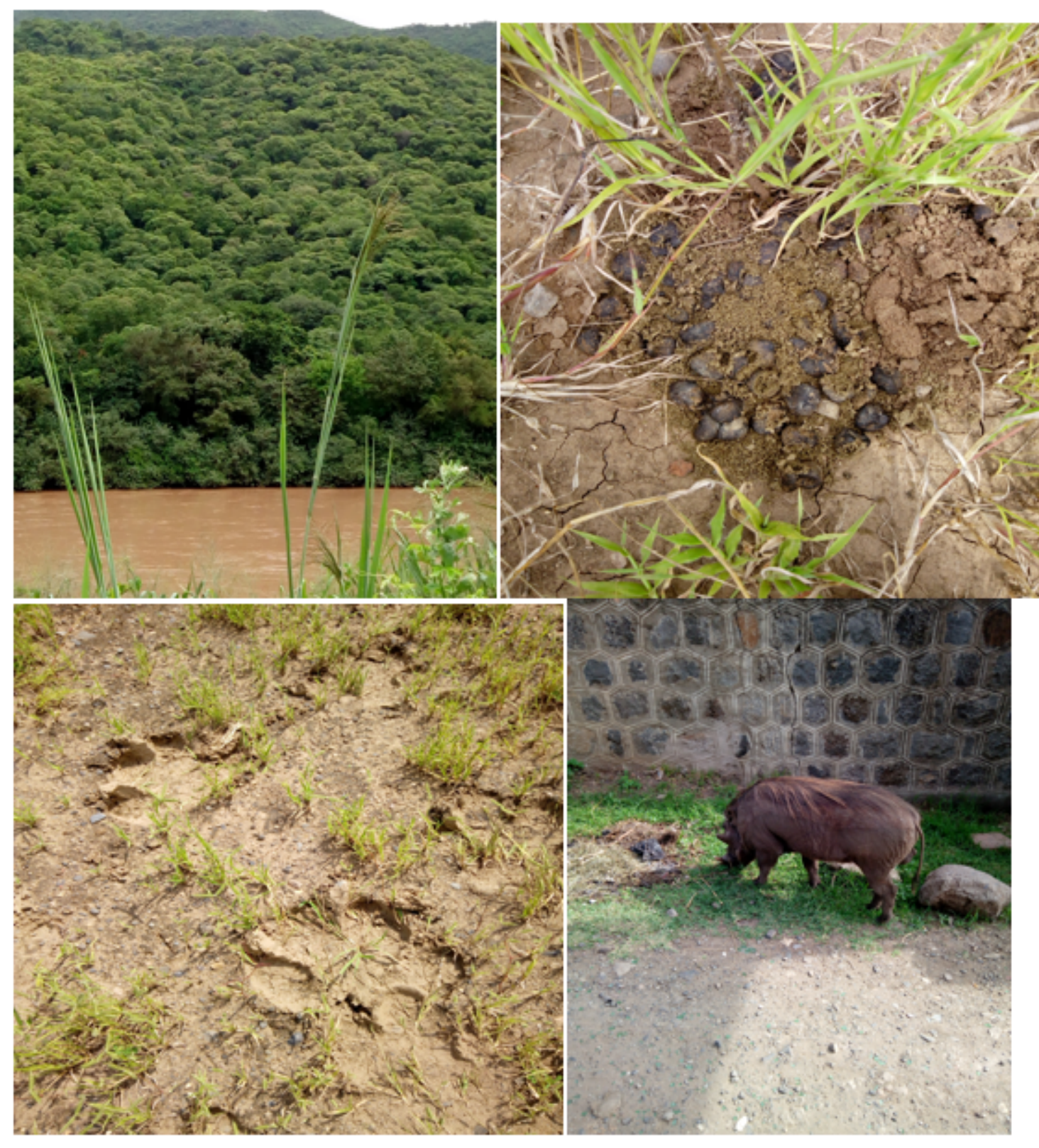

\section{Figure 4}

Forest, dung and hoof print of hippo and warthog observed downstream to Ghibe-III dam 